
\title{
3 Research Square \\ The Effects of Exercise Therapy Moderated by Sex in Rehabilitation of COVID-19
}

Linda Katharina Rausch ( $\sim$ linda.rausch@uibk.ac.at)

University of Innsbruck: Universitat Innsbruck https://orcid.org/0000-0002-1015-4033

\section{Bernhard Puchner}

Rehab Center Muenster, Department of Rehabilitation Research

\section{Jürgen Fuchshuber}

Psychiatry and Psychotherapy Departments of Valais Romand Hospital Center: Hopital Psychiatrique de Malevoz

\section{Barbara Seebacher}

Rehab Center Münster, Department of Rehabilitation Research

Judith Löffler-Ragg

Medical University of Innsbruck: Medizinische Universitat Innsbruck

\section{Stephan Pramsohler}

Hermann Buhl Institute for Hypoxia and Sleep Medicine Research

\section{Nikolaus C. Netzer}

University Ulm Medical Centre: Universitatsklinikum Ulm

\section{Martin Faulhaber}

University of Innsbruck: Universitat Innsbruck

\section{Research Article}

Keywords: Exercise Therapy, Rehabilitation, Sex Characteristics, COVID-19, Respiratory Function Tests, Whole Body Plethysmography, Six-Minute Walk Test

Posted Date: December 29th, 2021

DOl: https://doi.org/10.21203/rs.3.rs-1192916/v1

License: (c) (1) This work is licensed under a Creative Commons Attribution 4.0 International License. Read Full License 


\section{Abstract}

\section{Background}

Pulmonary rehabilitation serves as a key component in the recovery of COVID-19 and standardized exercise therapy programs in pulmonary rehabilitation have been shown to significantly improve physical performance and lung function parameters in post-acute COVID-19 patients. However, it has not been investigated if these positive effects are equally beneficial for both sexes, especially considering a more severe physical impact of COVID-19 in men when compared to women. Therefore, the purpose of this study was to analyze outcomes of a pulmonary rehabilitation program with respect to sex differences, in order to identify sex-specific pulmonary rehabilitation requirements.

Methods

Data of 233 patients were analyzed before and after a three-week standardized pulmonary rehabilitation program. Patients were admitted to rehabilitation due to post-acute COVID-19 illness and staged using the COVID-19 Severity Scale by Huang et al. (2021). Lung function parameters were assessed as part of the clinical routine using spirometry $\left(\mathrm{IC}_{\max }\right.$, maximal inspiratory capacity) and body plethysmography (FVC, forced vital capacity; $F_{E V}$, forced expiratory volume in the first second) and functional exercise capacity was measured by the Six-Minute Walk Test (6MWT). For the comparison of lung function and walking parameters by sex, Welch-ANOVA was used, as results of Levene's test suggested significant heteroscedasticity regarding the investigated parameters $(p>0.05)$. When comparing post-treatment $6 \mathrm{MWT}, \mathrm{FEV}_{1}$ and FCV to corresponding reference values, paired t-tests were used.

Results

At post-rehabilitation, $\mathrm{IC}_{\text {max }}, \mathrm{FVC}, \mathrm{FEV}_{1}$ and $6 \mathrm{MWT}$ has been improved in both sexes. Females showed a significantly smaller improvement in $\mathrm{FEV}_{1}$ and $\mathrm{IC}_{\max }\left(F=5.86, \omega^{2}=.02 ; \mathrm{p}<0.05\right)$ than males. There was no statistically significant difference in FVC and 6MWT performance improvements between men and women. After the rehabilitation stay, females made greater progress towards reference values of $6 \mathrm{MWT}$ $(T(231)=-3.04 ; p<0.01)$ and $\mathrm{FEV}_{1}(\mathrm{~T}(231)=2.83 ; \mathrm{p}<0.01)$ than males.

\section{Conclusions}

Sex differences in the improvement of lung function parameters seem to exist when completing a threeweek pulmonary rehabilitation program and should be considered when personalizing standardized exercise therapies in pulmonary rehabilitation.

Trial registration

this study was registered in the German Clinical Trials Register (DRKS00026936) on 2021/10/19. 


\section{Highlights}

After suffering from COVID-19, pulmonary rehabilitation has been suggested to improve lung function and functional exercise capacity in both sexes. Results from our study however showed greater improvement in particular lung function parameters $\left(\mathrm{IC}_{\max }\right.$ and $\left.\mathrm{FEV}_{1}\right)$ in men following a three-week pulmonary rehabilitation program, with women having been closer to a healthy status of functional exercise capacity than men.

\section{Background}

Since the corona virus disease 2019 (COVID-19) has been declared a pandemic in March 2020, healthcare providers have been globally challenged to manage disease spreading and maintain instant and long-term medical treatment for all affected individuals [1]. As the pandemic progresses, COVID-19related sex disparities have been observed. The risk of a severe progression of COVID-19 has consistently been found two times greater for men than for women worldwide, measured by the number of deaths, hospitalizations, intensive care unit stays and intubations for mechanical ventilation [2-4]. Especially men between the ages of 65 and 85 have dominated the prevalence of COVID-19-related deaths [5], probably associated with comorbidities such as obesity, hypertension or cardiovascular disease tending to affect men more frequently than women [6-8]. Potential reasons range from biological factors, including stronger female immune response to viral infections and protective properties of estrogen, to social factors e.g., higher alcohol consumption and enhanced smoking behavior in men [9-11].

A SARS-CoV-2 infection specifically affects the respiratory system and symptoms have been shown to be manifested six months to one year after hospital discharge $[12,13]$. Patients, predominantly males, who were seriously ill during their hospital stay had more severely impaired lung function capacities whereas lung diffusion impairment and fatigue or muscle weakness were symptoms mainly observed in women six months after their hospital discharge $[12,13]$. However, these patients may not have undergone inpatient rehabilitation following their acute hospital stay. Evidently, pulmonary rehabilitation has been promoted as a key treatment component after acute COVID-19 illness and applied successfully including standardized exercise therapy interventions connected to a multidisciplinary approach $[14,15]$. This has been shown in improved lung function parameters and functional exercise capacity of post-acute COVID19 patients after three to five weeks $[16,17]$. Especially respiratory exercise has led to a significant improvement in lung function and physical performance in elderly patients [18]. These findings emphasize the effectiveness of pulmonary rehabilitation reducing recovery time after burden of COVID19. So far however, it has not been investigated, if standardized pulmonary rehabilitation is equally efficacious in males and females in the post-acute stage after a COVID-19 infection. Therefore, based on sex disparities in former hospitalized COVID-19 patients [19,20], we aimed to analyze the outcomes of standardized pulmonary rehabilitation in post-acute COVID-19 patients with respect to sex-specific differences. The purpose of the study is to initiate a discourse with other researchers evaluating the relevance of sex-specific approaches in standardized rehabilitation treatments of COVID-19 patients. 


\section{Methods}

\section{Design and Data Source}

The retrospective case series contains data from post-acute COVID-19 patients who were admitted to a standardized three-week pulmonary rehabilitation program at the Clinic for Rehabilitation in Münster, Austria. They were admitted between the $1^{\text {st }}$ of March 2020 and $31^{\text {st }}$ of May 2021, due to a laboratory confirmed SARS-CoV-2 infection prior to rehabilitation, according to the definition of the Austrian Federal Ministry of Social Affairs \& Health Care. Initially, data of all eligible patients who underwent rehabilitation in this time frame were screened by a physician. Before data evaluation, data were pseudonymized and then extracted from the clinic information system (MP2 IT-Solutions, Austria). Data pseudonymization and extraction were carried out by one physician and one research assistant. Data privacy was guaranteed by an in-house data protection agreement made by a commissioner for data protection. Steps of the retrospective data analyses are shown in Figure 1. The research ethics committee of the Medical University of Innsbruck approved the study protocol (1066/2021) and the study was registered at the German Clinical Trials Register (ID: DRKS00026936).

\section{Characteristics of Patients' Data}

Records from post-acute COVID-19 patients with the principal diagnosis ICD U.07.1 (COVID-19) were analyzed. Anthropometric data as well as secondary diagnoses which were present before the COVID-19 infection were included in the analyses. Secondary diagnoses included cardiovascular and cerebrovascular diseases, chronic kidney diseases, obstructive pulmonary disease (COPD), bronchial asthma, as well as diabetes and hypertension. These diagnoses were documented by the treating physician. (Pre-) diabetes was defined by an elevated hemoglobin A1c value or prescribed anti-diabetic medication according to the International Diabetes Federation (IDF) [21]. Hypertension was defined by > $130 / 80 \mathrm{mmHg}$ or prescribed antihypertensive medication according to the International Society of Hypertension Guidelines [22]. Patients were admitted to pulmonary rehabilitation as soon as they were physically stable without the need of continuous supervision, invasive or non-invasive ventilation. They could be admitted after being tested negative twice by real-time polymerase chain reaction via swab. If patients terminated their stay before completing the three-week program or if admission and discharge measurements were incomplete, their data were excluded from analyses (see Figure 1).

After inclusion, patient's data were categorized according to Huang's COVID-19 severity scales (Huang, 2021):

Scale 1: not admitted to hospital before rehabilitation stay with resumption of normal activities

Scale 2: not admitted to hospital before rehabilitation stay, but unable to resume normal activities

Scale 3: admitted to hospital before rehabilitation stay and not requiring supplemental oxygen

Scale 4: admitted to hospital before rehabilitation stay, but requiring supplemental oxygen 
Scale 5: admitted to hospital before rehabilitation stay requiring high flow nasal cannula (HFNC), noninvasive mechanical ventilation (NIV) or both

Scale 6: admitted to hospital before rehabilitation stay requiring extracorporeal membrane oxygenation, invasive mechanical ventilation (IMV) or both

Scale 7: death (not applicable)

Included Measurement Data

After their admission to rehabilitation, patients were assessed following a standardized clinical routine. As part of this clinical routine, the Six-Minute Walk Test (6MWT) and pulmonary function testing were carried out at the beginning and at the end of the three-week rehabilitation stay. The 6MWT is a welldocumented standardized assessment used to assess walking endurance and functional exercise capacity and has been used to assess the response to medical interventions in diverse patient groups [23]. It was executed by an experienced and well-instructed physiotherapy staff member according to the guidelines of the American Thoracic Society (ATS) [24]. 6MWT outcome values were compared to 6MWT reference values for recovered healthy adults according to Enright et al., [25]. The corresponding reference values for each participant were calculated according to reference equations for men: 6MWD $=(7.57 \mathrm{x}$ height $_{(\mathrm{cm})}-\left(5.02 \times\right.$ age $\left._{(\text {years })}\right)-\left(1.76 \mathrm{x}\right.$ weight $\left._{(\mathrm{kg})}\right)-309 \mathrm{~m}$; for women: 6MWD $=\left(2.11 \mathrm{x} \mathrm{height}_{(\mathrm{cm})}\right)-$ $2.29 \times$ weight $\left._{(\mathrm{kg})}\right)-\left(5.78 \times\right.$ age $\left._{(\text {years })}\right)+667 \mathrm{~m} \mathrm{[25]}$. The difference in pre and post measurements of the 6MWT were compared to the minimal clinically important difference across multiple patient groups [26] and to reference values for patients suffering from acute respiratory distress syndrome or having survived acute respiratory distress syndrome [27]. After the 6MWT, maximal inspiratory capacity $\left(\mathrm{IC}_{\max }\right)$ was measured using a manometer connected to a PEP-RMT-System (Positive Expiratory PressureRespiratory Muscle Training-System) (Mediplast, Malmö, Sweden). Further pulmonary functions were tested using body-plethysmography (Master Screen Body, Traeger GmbH, Hoechberg, Germany). Measurements were carried out by an experienced physician according to recent updated guidelines by the ATS [28] and the European Respiratory Society (ERS) $[29,30]$.

Primary outcomes included the 6MWT, IC $\mathrm{I}_{\max }$ measured by the PEP-RMT-System as well as Forced Vital Capacity (FVC) and Forced Expiratory Volume in the first second $\left(\mathrm{FEV}_{1}\right)$ assessed by bodyplethysmography. FVC and $\mathrm{FEV}_{1}$ were compared to calculated reference values of bodyplethysmography. Secondary outcomes included the number and type of exercise therapy sessions throughout the patients' rehabilitation visit.

\section{Exercise Therapy Interventions}

All post-acute COVID-19 patients admitted to pulmonary rehabilitation followed a standardized program with a duration of at least three weeks, including exercise therapy sessions on 5-6 weekdays. Each week, 
patients participated in a maximum of 3 exercise therapy sessions per day (Monday to Friday). The exercise therapy sessions consisted of individual respiratory muscle training, pulmonary group exercises, individual strength exercises ( 3 to 5 exercises for large muscle groups in three series of 8 to 12 repetitions per exercise with or without weight machines), individual endurance training (cycling, treadmill, in and outdoor walking) and relaxation group exercises. Intensities and intervals of endurance training were based on the results of the 6MWT performance. For respiratory muscle training, a hand-held resistance device was used (PEP-RMT-System, Mediplast, Malmö, Sweden) for 3 sets of 10 breaths each and a 1minute rest between sets. Each exercise session lasted for 30-45 minutes and was supervised by a sport scientist or a physiotherapist. The amount and type of the group exercise therapy sessions and the amount of individual physiotherapy sessions were determined by the physicians in charge.

\section{$\underline{\text { Statistical Analyses }}$}

Descriptive characteristics and secondary diagnoses of males and females were presented as mean with standard deviation or percentages. Spearman's rank correlations between COVID-19 severity and secondary diagnoses were calculated, as COVID-19 severity was categorized by the ordinally scaled COVID-19 Severity Scale (Huang et al., 2021). Spearman's rank correlations were also calculated between the number of respiratory muscle training sessions and lung function parameters $\left(\mathrm{FEV}_{1}, \mathrm{FVC}\right.$

and $\left.I C_{\max }\right)$ as well as the $6 \mathrm{MWT}$. For the comparison of functional exercise capacity (6MWT) and lung function parameters ( $\mathrm{FEV}_{1}, \mathrm{FVC}$ and $\mathrm{IC}_{\mathrm{max}}$ ) by sex, Welch-ANOVA was used, as results of Levene's test suggested significant heteroscedasticity regarding the investigated parameters $(p>0.05)$. When comparing post-treatment 6MWT, FEV1 and FCV to corresponding reference values, paired t-tests were used.

\section{Results}

In total, 233 previously confirmed COVID-19 cases were included in the analyses i.e., 94 (40.4\%) females and $139(59.6 \%)$ males. The mean number of rehabilitation days was $21.51( \pm 2.22)$ for females and $21.86( \pm 3.75)$ for males with no significant differences between groups. Considering the previous COVID19 infection, females were significantly less affected by COVID-19 severity according to Huang's severity stages than males $(p=0.004)$. COVID-19 severity and the comorbidity of bronchial asthma exhibited a weak negative correlation $(r=-0.16 ; p<0.05)$, while cerebrovascular diseases showed a weak positive correlation with COVID-19 severity $(r=0.16 ; p<0.05)$. No further significant correlations between secondary diagnoses and COVID-19 severity were found (all $p>0.05$ ). Furthermore, neither smoking status nor obesity $(\mathrm{BMI} \geq 25)$ was significantly associated with a more severe COVID-19 history ( $p$ > 0.05). Details about the COVID-19 severity, patients' characteristics and secondary diagnoses are shown in Table 1. 
Table 1

Comparison of descriptive measures of patients by sex

\begin{tabular}{|c|c|c|c|c|c|c|}
\hline \multirow[b]{2}{*}{ Category } & \multicolumn{2}{|c|}{ Females $(n=94)$} & \multicolumn{2}{|c|}{ Males $(n=139)$} & \multirow[b]{2}{*}{$\mathrm{T}(\mathrm{df})$} & \multirow[b]{2}{*}{$\mathrm{p}$} \\
\hline & M & SD & M & SD & & \\
\hline Age (years) & 61.50 & 12.81 & 61.69 & 11.55 & $-0.12(231)$ & NS \\
\hline Weight difference (kg) & -0.58 & 1.49 & -0.36 & 2.57 & $-0.81(220.88)$ & NS \\
\hline $\mathrm{BMI}_{\text {Pre }}\left(\mathrm{kg} / \mathrm{m}^{2}\right)$ & 29.10 & 7.04 & 28.47 & 5.09 & $0.73(153.77)$ & NS \\
\hline \multirow[t]{3}{*}{$\mathrm{BMI}_{\text {Post }}\left(\mathrm{kg} / \mathrm{m}^{2}\right)$} & 28.93 & 6.91 & 28.39 & 5.00 & $0.65(152.01)$ & NS \\
\hline & \multicolumn{2}{|c|}{ Females $(n=94)$} & \multicolumn{2}{|c|}{ Males $(n=139)$} & & \\
\hline & M & $\%$ & M & $\%$ & $\chi^{2}(\mathrm{df})$ & $\mathrm{p}$ \\
\hline Smoking status & & & & & 2.61(2) & NS \\
\hline Non-smoker & 51 & 54.26 & 63 & 45.32 & & \\
\hline Current smoker & 2 & 2.13 & 1 & 0.72 & & \\
\hline Former smoker & 40 & 42.55 & 71 & 51.08 & & \\
\hline \multicolumn{7}{|l|}{ Comorbidities } \\
\hline Hypertension & 37 & 39.4 & 72 & 51.8 & $3.48(1)$ & NS \\
\hline Diabetes & 38 & 40.4 & 65 & 46.76 & $0.91(1)$ & NS \\
\hline Cardiovascular disease & 35 & 37.2 & 55 & 39.57 & $0.13(1)$ & NS \\
\hline Cerebrovascular disease & 6 & 6.4 & 7 & 5.04 & $0.19(1)$ & NS \\
\hline COPD & 9 & 9.6 & 9 & 6.47 & $0.76(1)$ & NS \\
\hline Bronchial asthma & 17 & 18.1 & 17 & 12.23 & $1.54(1)$ & NS \\
\hline Chronic kidney disease & 7 & 7.4 & 13 & 9.35 & $0.26(1)$ & NS \\
\hline COVID-19 Severity Scale* & & & & & $15.63(4)$ & 0.004 \\
\hline Scale 2 & 35 & 37.2 & 28 & 20.14 & & \\
\hline Scale 3 & 28 & 29.8 & 30 & 21.58 & & \\
\hline Scale 4 & 10 & 10.6 & 20 & 14.39 & & \\
\hline Scale 5 & 9 & 9.6 & 28 & 20.14 & & \\
\hline Scale 6 & 12 & 12.8 & 33 & 23.74 & & \\
\hline
\end{tabular}




\section{Females $(n=94) \quad$ Males $(n=139)$}

Notes. $\mathrm{BMI}_{\mathrm{Pre}}=$ Body Mass Index at rehabilitation entry, $\mathrm{BMI}_{\text {Post }}=$ Body Mass Index at rehabilitation discharge; $M(S D)=$ mean \pm standard deviation; $T(d f)$ = t-distribution with degrees of freedom; $N S=$ level of significance $>0.05 ; \chi^{2}(\mathrm{df})=$ chi-square value with degrees of freedom; COPD $=$ Chronic Obstructive Pulmonary Disease;

*defined as Scale 2 = not admitted to hospital before rehabilitation stay, but unable to resume normal activities; Scale 3 = admitted to hospital before rehabilitation stay and not requiring supplemental oxygen; Scale 4 = admitted to hospital before rehabilitation stay but requiring supplemental oxygen; Scale $5=$ admitted to hospital before rehabilitation stay requiring HFNC, NIV or both; Scale $6=$ admitted to hospital before rehabilitation stay requiring invasive mechanical ventilation.

\section{Exercise Therapy Sessions}

Within the 3 weeks of pulmonary rehabilitation, females completed an average of 34.29 and males an average of 35.23 exercise therapy sessions, with no significant differences between sexes $(p=0.284)$. The different types of exercise therapy (i.e. strength, endurance and relaxation exercises and respiratory muscle training) were equally distributed between sexes, except for a trend $(p=0.056)$ in males receiving more sessions of respiratory muscle training when compared to females. A detailed description of exericse therapy sessions is provided in Table 2. Additionally, females received 6.88 and males 7.42 individual physiotherapy sessions on average. No significant correlations were found between the number of respiratory muscle training sessions and lung function parameters $\left(\mathrm{FEV}_{1}, \mathrm{FVC}\right.$ and $\left.\mathrm{IC}_{\text {max }}\right)$ as well as the 6MWT (all $p>0.05$ ).

Table 2

Number of delivered exercise therapy sessions to females and males

\begin{tabular}{|llll|}
\hline & & Female $(\mathbf{n}=\mathbf{9 4})$ & Male $(\mathbf{n = 1 3 9 )}$ \\
\hline Respiratory muscle exercise* & $\mathrm{M}(\mathrm{SD})$ & $6.82( \pm 2.08)$ & $7.39( \pm 2.31)$ \\
\hline Pulmonary group exercise & $\mathrm{M}(\mathrm{SD})$ & $6.37( \pm 2.60)$ & $6.71( \pm 2.57)$ \\
\hline Strength exercise & $\mathrm{M}(\mathrm{SD})$ & $6.40( \pm 2.79)$ & $6.18( \pm 2.77)$ \\
\hline Endurance exercise & $\mathrm{M}(\mathrm{SD})$ & $9.84( \pm 3.49)$ & $10.38( \pm 2.67)$ \\
\hline Relaxation exercise & $\mathrm{M}(\mathrm{SD})$ & $4.85( \pm 1.89)$ & $4.58( \pm 2.13)$ \\
\hline All training therapy sessions & $\mathrm{M}(\mathrm{SD})$ & $34.29( \pm 7.74)$ & $35.23( \pm 5.66)$ \\
\hline Notes. ${ }^{*}$ T(df) $=-1.92(231), \mathrm{p}=0.056 ; \mathrm{M}(\mathrm{SD})=$ mean \pm standard deviation \\
\hline
\end{tabular}

Both males and females showed a statistically significant improvement in walking distance after the 3 week rehabilitation $(T(232)=-16.67 ; p<0.001 ; d=0.48)$. The difference was not sex dependent $(p>.05$; see Table 3). When comparing the 6-minute walking distance (6MWD) at rehabilitation discharge to 
corresponding reference values for healthy persons (Enright et al., 1998), males showed significantly reduced walking distances compared to females $(T(231)=-3.04 ; p<0.01 ; d=0.41)$. In correspondence to that, males exhibited an actual average distance of 498.08 meters $(\mathrm{m}) \mathrm{vs}$. a reference average distance of $573.66 \mathrm{~m}(\mathrm{p}<0.01)$, as compared to female patients whose actual and reference 6MWD values were not significantly different (average $477.29 \mathrm{~m}$ vs. $493.93 \mathrm{~m} ; \mathrm{p}=0.259$ ). 
Table 3

Sex differences (Welch-ANOVA) in outcome measures.

\section{Female $(n=94) \quad$ Male $(n=139)$}

$\begin{array}{lllllllllllllll}\text { Measures } & M & \text { SD } & M & \text { SD } & F & \text { df } & \omega^{2} & p\end{array}$

6MWT

$\begin{array}{llllllllll}\text { Pre } & 405.80 & 134.70 & 435.47 & 153.19 & 2.43 & 1, & 215.65 & - & 0.14 \\ \text { Post } & 477.29 & 130.76 & 498.08 & 148.55 & 1.27 & 1, & 215.53 & - & 0.32 \\ \text { Difference } & 71.49 & 69.75 & 62.61 & 53.50 & 1.09 & 1, & 164.21 & - & 0.33\end{array}$

FVC

\begin{tabular}{llllllllll} 
Pre & 2.80 & 0.77 & 3.68 & 1.00 & 56.68 & 1, & 226.52 & 0.24 & 0.00 \\
Post & 2.95 & 0.76 & 3.90 & 0.98 & 69.47 & 1, & 226.43 & 0.29 & 0.00 \\
\hline Difference & 0.14 & 0.35 & 0.22 & 0.46 & 2.03 & 1, & 228.15 & - & 0.17
\end{tabular}

$\mathrm{FEV}_{1}$

\begin{tabular}{llllllllll} 
Pre & 2.29 & 0.66 & 2.98 & 0.81 & 51.47 & 1, & 223.33 & 0.22 & 0.00 \\
\hline Post & 2.37 & 0.62 & 3.17 & 0.83 & 69.80 & 1, & 228.26 & 0.30 & 0.00 \\
\hline Difference & 0.09 & 0.25 & 0.19 & 0.39 & 5.86 & 1, & 230.81 & 0.02 & 0.02 \\
\hline
\end{tabular}

$\mathrm{FEV}_{1} / \mathrm{FVC}$

\begin{tabular}{|c|c|c|c|c|c|c|c|c|c|}
\hline Pre & 82.42 & 0.04 & 81.72 & 9.57 & 0.25 & 1, & 180.45 & - & 0.62 \\
\hline Post & 80.82 & 0.04 & 81.67 & 10.17 & 0.30 & 1, & 154.74 & - & 0.59 \\
\hline Difference & 1.60 & 0.04 & 0.04 & 13.22 & 1.39 & 1, & 145.93 & - & 0.24 \\
\hline $\mathrm{IC}_{\max }$ & \multicolumn{2}{|c|}{ Female $(\mathrm{n}=94)$} & \multicolumn{7}{|c|}{ Male $(n=136)$} \\
\hline Pre & 33.09 & 13.78 & 50.06 & 20.69 & 55.75 & 1, & 227.72 & 0.24 & 0.00 \\
\hline Post & 49.02 & 19.03 & 72.99 & 24.34 & 69.99 & 1, & 224.48 & 0.30 & 0.00 \\
\hline Difference & 15.94 & 14.07 & 22.93 & 21.44 & 8.93 & 1, & 227.46 & 0.03 & 0.00 \\
\hline
\end{tabular}

\section{Lung Function Testing}

Both male and female patients improved their maximal inspiration capacity $\left(\mathrm{IC}_{\max }\right)$ during the three weeks of rehabilitation $(T(229)=15.972 ; p<0.001 ; d=1.05)$, however, the improvement was 
significantly superior in males as compared to females $\left(F(1,227.46)=8.93 ; p>0.01 ; \omega^{2}=0.03\right)$. While no sex related differences were found regarding the ratio of $\mathrm{FEV}_{1} / \mathrm{FVC}(\mathrm{p}>0.05)$, male patients exhibited higher pre $\left(F(1,226.52)=56.68, p<0.001 ; \omega^{2}=0.24\right)$ and post treatment $F V C(F(1,226.43)=69.47 ; p<$ $\left.0.001 ; \omega^{2}=0.29 ;\right)$. However, no significant sex-interaction was observed $(p>0.05)$. Similarly, the results suggested higher pre $\left(F(1,223.33)=51.47 ; p<0.001 ; \omega^{2}=0.22\right)$ as well as post treatment $F_{1} V_{1}(F$ $\left.(1,228.26)=69.80 ; p<0.001 ; \omega^{2}=0.30\right)$ in males compared to females. Moreover, female patients showed a significantly smaller difference regarding the improvement in $\operatorname{FEV}_{1}$ than males $(F(1,230.81)=$ $5.86 ; p<0.05 ; \omega^{2}=0.02$ see Figure 2). The results of primary outcome measures are detailed in Table 3 .

Compared to individual corresponding reference values, patients showed significantly reduced FVC (pretreatment: $\mathrm{T}(232)=-11.19 ; \mathrm{p}<0.001 ; \mathrm{d}=0.73$; posttreatment: $\mathrm{T}(232)=-4.05 ; \mathrm{p}<0.001 ; \mathrm{d}=0.27$ ) and FEV $_{1}$ (pretreatment: $\mathrm{T}(232)=-10.22 ; \mathrm{p}<0.001 ; \mathrm{d}=0.67$; posttreatment: $\mathrm{T}(232)=-7.00 ; \mathrm{p}<0.001 ; \mathrm{d}=$ 0.46 ) before and after the three-week rehabilitation program.

While there was no sex related difference in posttreatment FVC $(p>0.05)$, female patients exhibited significantly lower differences between actual and correpsonding reference values regarding pretreatment FVC $(T(228.51)=5.05 ; p<0.001 ; d=0.67)$ and pre- as well as posttreatment $\mathrm{FEV}_{1}$ (pretreatment: $\mathrm{T}(228.85)=4.36 ; \mathrm{p}<0.001 ; \mathrm{d}=0.58$; posttreatment: $\mathrm{T}(231)=2.83 ; \mathrm{p}<0.01 ; \mathrm{d}=0.38$ ). Details about $\mathrm{FEV}_{1}$ reference value and actual value changes are shown in Figure 3.

\section{Discussion}

This study highlights sex disparities in positive outcomes of lung function parameters after a standardized 3-week pulmonary rehabilitation in a cohort of 233 post-acute COVID-19 patients. Male patients showed significantly greater improvements in specific lung function parameters i.e. $\mathrm{FEV}_{1}$ and $I_{\max }$ than female patients. Furthermore, values from female patients corresponded more closely with $\mathrm{FEV}_{1}$ normative values than male patients.

These sex disparities could be associated with the clinical representation of the investigated COVID-19 cohort. Male patients were significantly more affected by COVID-19 during their acute hospital stay prior to pulmonary rehabilitation than female patients, matching the results of other studies that have investigated COVID-19 hospital cohorts [2,3,31]. As a possible consequence, baseline FEV 1 and FVC values in men were poorer than those of women prior to their rehabilitation, with respect to individual normative values. Therefore, standardized exercise therapy interventions in pulmonary rehabilitation might have had a greater effect in men as compared to women, due to a standard exercise principle: there is a greater likelihood of a pulmonary function improvement during a training period in the more untrained and the more disease affected people than in the more trained and less disease affected cohort, respectively [32]. Skeletal muscle mass and physical fitness could also represent confounding variables which influence exercise training outcomes. In addition, patients with comorbidities such as chronic obstructive pulmonary disease (COPD) and bronchial asthma are suggested to lead to reduced 
values of $\mathrm{FEV}_{1}$ and $\mathrm{IC}_{\mathrm{max}}$. However, in our study cohort, the same number of women $(\mathrm{n}=9)$ and men $(\mathrm{n}=$ 9) were affected by these comorbidities, which possibly hampered the evaluation of sex differences.

Further, morphological differences between men and women need to be considered when interpreting the greater improvement in $\mathrm{FEV}_{1}$ and $\mathrm{IC}_{\max }$ in men. Smaller lung size and proportionally smaller airways in women, as well as different size and shapes of the lung and rib cage tend to lead to functional differences. For example, an expiratory flow limitation and greater cost of breathing has been observed during exercise in women, including particular activation of inspiratory muscles [33, 34]. At a given minute ventilation women have to perform greater respiratory work due to smaller airways, which may also induce different patterns of respiratory muscle activation in order to distribute the ventilation load [35]. Therefore, muscles such as sternocleidomastoid or the scalene muscles could be activated to a greater extent by women in order to assist the diaphragm work. This might result in less efficient general activation of respiratory muscles as well as to a conditioned response to respiratory muscle exercise [35, 36]. However, these functional implications of sex differences in respiratory muscle activation remain to be fully investigated [33].

In this regard, the trend of a greater number of respiratory muscle exercise sessions in men has to be mentioned. The overall number of exercise therapy sessions did not differ between sexes however. A reason for this uneven, yet not significantly different distribution could be the greater need of respiratory muscle exercise in men, due to their more severe COVID-19 symptoms when compared to women. In inpatient pulmonary rehabilitation, an individual approach is primarily used, with applying exercise programs as needed by each patient for their individual physical improvement $[15,16]$. The significant $\mathrm{FEV}_{1}$ and non-significant $\mathrm{FVC}$ improvement only in men could be related to the previous finding of a significant $\mathrm{FEV}_{1}$ reduction in patients with cardiorespiratory pathologies; for these diseases, a higher prevalence has been reported in males compared to females [8, 37]. However, the present COVID-19 patient male and female cohort were similar with regard to pre-existing cardiorespiratory pathologies.

The significant improvement in the 6MWT as a performance measure of exercise capacity in both sexes was in line with Liu et al., and Spielmanns et al., who reported similar improvements in severe postCOVID-19 patients and elderly patients with COVID-19 $[17,18]$. The majority of investigated patients of this study's cohort exceeded the threshold of $54 \mathrm{~m}$ for a clinically significant change, as well as the newly proposed 14 to $30.5 \mathrm{~m}$ across multiple patient groups [26,38]. For patients suffering from acute respiratory distress syndrome or survivors of acute respiratory distress syndrome, a minimal clinically important difference (MCID) of 20 to $30 \mathrm{~m}$ was proposed [27]. However, when the 6MWD was compared to corresponding normative values for healthy people[25] at rehabilitation discharge, there was a discrepancy between male and female patients, with singificantly poorer walking endurance in males. From this could be derived that it is women rather than men who may be closer to a healthy status of functional exercise capacity after a three-week pulmonary rehabilitation program.

The effectiveness of a three to six-week standardized pulmonary rehabilitation after COVID-19 has been shown in previous studies and the number and type of comorbidities of this study's COVID-19 patient 
cohort are in line with others, as well as the improvement of total values of lung function parameters [17, $18,39,40]$. Despite the demonstrated effectiveness, the failure of lung function parameters and functional exercise capacity reaching normative values at rehabilitation discharge majorly underlines the necessity of long-lasting pulmonary rehabilitation in former COVID-19 patients. The usual publicly financed time frame for inpatient pulmonary rehabilitation in Austria does not exceed five to six weeks [41]. Further gains in lung function and exercise capacity could probably be promoted through longer pulmonary rehabilitation programs offered in health care settings.

We acknowledge that the present study has several limitations. First, we cannot report on the causality of the observed findings due to the observational study design. Second, caution is advised when claiming an overall improvement in lung function parameters and functional exercise capacity without an appropriate non-COVID-19 control group. The main focus of this study is the inter-subject comparison between sexes. Third, we cannot exclude an impact of additional medical treatment measures on the outcome of functional exercise capacity and lung function parameters in regard to the multidisciplinary rehabilitation plan. Fourth, it was not possible to extract and interpret diffusion capacity of the lungs due to missing data, associated with the nature of retrospective data collection. Furthermore, this study exclusively investigated physical function of rehabilitated COVID-19 patients whereas psychological aspects such as quality of life could not be evaluated, which contribute essentially in the recovery of COVID-19 $[42,43]$. Finally, long-term results of inpatient pulmonary rehabilitation on sex differences cannot be derived from this data.

\section{Perspectives and Significance}

This study highlights differences in lung function improvement and outcomes of functional exercise capacity between sexes. Men showed greater effects from pulmonary rehabilitation in regard to particular lung function parameters $\left(\mathrm{IC}_{\mathrm{max}}\right.$ and $\left.\mathrm{FEV}_{1}\right)$ than women and women are more likely to reach corresponding reference values than men. This knowledge could be of importance when designing pulmonary rehabilitation programs or when conducting respiratory muscle exercise sessions in a group setting, where an individual approach to each patient cannot be as guaranteed as in an one-on-one exercise session.

However, further studies are needed to explore the effects of pulmonary rehabilitation programs for both sexes in the long-term. Therefore, a follow-up study from the same cohort will be conducted including former COVID-19 patients after six months of their rehabilitation stay.

\section{Conclusions}

Although pulmonary rehabilitation programs have shown to be beneficial in the recovery from COVID-19, men appear to benefit more than women, with respect to particular lung function parameters $\left(\mathrm{FEV}_{1}\right.$ and $\left.I C_{\max }\right)$. Furthermore, women who previously suffered from COVID-19 and subsequently underwent 
rehabilitation treatment, seem to have better lung function parameters and functional exercise capacity than men compared to corresponding reference values.

\section{Declarations}

\section{Ethics approval}

The retrospective data collection and analysis was approved by the ethics committee of the Medical University of Innsbruck, Austria on the $25^{\text {th }}$ of May 2021 under the reference number 1066/2021 and was performed in accordance with the Declaration of Helsinki.

Consent for publication

not applicable

Availability of data and materials

All data generated or analysed during this study are included in this published article (and its supplementary information files).

Competing interests

The authors declare that they have no competing interest.

\section{Funding}

The study is supported by the Early-Stage-Funding Program of the University of Innsbruck.

\section{$\underline{\text { Authors' contributions }}$}

LKR and BP designed the study and collected the data. LKR and JF performed the statistical analysis. LKR, JF, BP interpreted the data. LKR wrote the manuscript draft. BS, JLR, SP, NN substantially revised the manuscript. MF supervised the study. All authors read and approved the final manuscript.

\section{Acknowledgements}

We want to thank employees of the Rehab Clinic Muenster under the leadership of Dr. Christian Brenneis for the cooperation and technical support in retreiving the data.

\section{References}

1. Cucinotta D, Vanelli M. WHO Declares COVID-19 a Pandemic. Acta Biomed. 2020;91:157-60. doi:10.23750/abm.v91i1.9397. 
2. Richardson S, Hirsch JS, Narasimhan M, Crawford JM, McGinn T, Davidson KW, et al. Presenting Characteristics, Comorbidities, and Outcomes Among 5700 Patients Hospitalized With COVID-19 in the New York City Area. JAMA. 2020;323:2052-9. doi:10.1001/jama.2020.6775.

3. Grasselli G, Zangrillo A, Zanella A, Antonelli M, Cabrini L, Castelli A, et al. Baseline Characteristics and Outcomes of 1591 Patients Infected With SARS-CoV-2 Admitted to ICUs of the Lombardy Region, Italy. JAMA. 2020;323:1574-81. doi:10.1001/jama.2020.5394.

4. Guan W-J, Ni Z-Y, Hu Y, Liang W-H, Ou C-Q, He J-X, et al. Clinical Characteristics of Coronavirus Disease 2019 in China. N Engl J Med. 2020;382:1708-20. doi:10.1056/NEJMoa2002032.

5. Nasiri MJ, Haddadi S, Tahvildari A, Farsi Y, Arbabi M, Hasanzadeh S, et al. COVID-19 Clinical Characteristics, and Sex-Specific Risk of Mortality: Systematic Review and Meta-Analysis. Front Med (Lausanne). 2020;7:459. doi:10.3389/fmed.2020.00459.

6. Alberca RW, Oliveira LdM, Branco, Anna Cláudia Calvielli Castelo, Pereira NZ, Sato MN. Obesity as a risk factor for COVID-19: an overview. Crit Rev Food Sci Nutr. 2021;61:2262-76. doi:10.1080/10408398.2020.1775546.

7. Mauvais-Jarvis F, Aging. Male Sex, Obesity, and Metabolic Inflammation Create the Perfect Storm for COVID-19. Diabetes. 2020;69:1857-63. doi:10.2337/dbi19-0023.

8. Banfi P, Garuti G, Diaz de Teran T, Ruiz J, Ferraioli G, Russo G, et al. Differences between sexes concerning COVID-19-related pneumonia. Panminerva Med. 2021. doi:10.23736/S00310808.21.04165-3.

9. Capuano A, Rossi F, Paolisso G. Covid-19 Kills More Men Than Women: An Overview of Possible Reasons. Front Cardiovasc Med. 2020;7:131. doi:10.3389/fcvm.2020.00131.

10. Channappanavar R, Fett C, Mack M, Eyck PP ten, Meyerholz DK, Perlman S. Sex-Based Differences in Susceptibility to Severe Acute Respiratory Syndrome Coronavirus Infection. J Immunol. 2017;198:4046-53. doi:10.4049/jimmunol.1601896.

11. Elgendy IY, Pepine CJ. Why are women better protected from COVID-19: Clues for men? Sex and COVID-19. Int J Cardiol. 2020;315:105-6. doi:10.1016/j.ijcard.2020.05.026.

12. Huang $C$, Huang $L$, Wang $Y$, Li X, Ren L, Gu X, et al. 6-month consequences of COVID-19 in patients discharged from hospital: a cohort study. Lancet. 2021;397:220-32. doi:10.1016/S01406736(20)32656-8.

13. Huang $L$, Yao Q, Gu X, Wang Q, Ren L, Wang Y, et al. 1-year outcomes in hospital survivors with COVID-19: a longitudinal cohort study. Lancet. 2021;398:747-58. doi:10.1016/S01406736(21)01755-4.

14. Simpson R, Robinson L. Rehabilitation After Critical Illness in People With COVID-19 Infection. Am J Phys Med Rehabil. 2020;99:470-4. doi:10.1097/PHM.0000000000001443.

15. Sonnweber T, Sahanic S, Pizzini A, Luger A, Schwabl C, Sonnweber B, et al. Cardiopulmonary recovery after COVID-19 - an observational prospective multi-center trial. Eur Respir J. 2020. doi:10.1183/13993003.03481-2020. 
16. Puchner B, Sahanic S, Kirchmair R, Pizzini A, Sonnweber B, Wöll E, et al. Beneficial effects of multidisciplinary rehabilitation in post-acute COVID-19 - an observational cohort study. Eur J Phys Rehabil Med. 2021. doi:10.23736/S1973-9087.21.06549-7.

17. Spielmanns M, Pekacka-Egli A-M, Schoendorf S, Windisch W, Hermann M. Effects of a Comprehensive Pulmonary Rehabilitation in Severe Post-COVID-19 Patients. Int J Environ Res Public Health. 2021. doi:10.3390/ijerph18052695.

18. Liu K, Zhang W, Yang Y, Zhang J, Li Y, Chen Y. Respiratory rehabilitation in elderly patients with COVID-19: A randomized controlled study. Complement Ther Clin Pract. 2020;39:101166. doi:10.1016/j.ctcp.2020.101166.

19. Quaresima V, Scarpazza C, Sottini A, Fiorini C, Signorini S, Delmonte OM, et al. Sex differences in a cohort of COVID-19 Italian patients hospitalized during the first and second pandemic waves. Biol Sex Differ. 2021;12:45. doi:10.1186/s13293-021-00386-z.

20. Yoshida Y, Gillet SA, Brown MI, Zu Y, Wilson SM, Ahmed SJ, et al. Clinical characteristics and outcomes in women and men hospitalized for coronavirus disease 2019 in New Orleans. Biol Sex Differ. 2021;12:20. doi:10.1186/s13293-021-00359-2.

21. Unwin N, Shaw J, Zimmet P, Alberti, K G M M. Impaired glucose tolerance and impaired fasting glycaemia: the current status on definition and intervention. Diabet Med. 2002;19:708-23. doi:10.1046/j.1464-5491.2002.00835.x.

22. Mancia G, Dominiczak A. The new International Society of Hypertension guidelines on hypertension. J Hypertens. 2020;38:981. doi:10.1097/HJH.0000000000002490.

23. Mänttäri A, Suni J, Sievänen $H$, Husu P, Vähä-Ypyä H, Valkeinen $H$, et al. Six-minute walk test: a tool for predicting maximal aerobic power (VO(2) max) in healthy adults. Clin Physiol Funct Imaging. 2018. doi:10.1111/cpf.12525.

24. ATS statement. guidelines for the six-minute walk test. Am J Respir Crit Care Med. 2002;166:111-7. doi:10.1164/ajrccm.166.1.at1102.

25. Enright PL, Sherrill DL. Reference equations for the six-minute walk in healthy adults. Am J Respir Crit Care Med. 1998;158:1384-7. doi:10.1164/ajrccm.158.5.9710086.

26. Bohannon RW, Crouch R. Minimal clinically important difference for change in 6-minute walk test distance of adults with pathology: a systematic review. J Eval Clin Pract. 2017;23:377-81. doi:10.1111/jep.12629.

27. Chan KS, Pfoh ER, Denehy L, Elliott D, Holland AE, Dinglas VD, Needham DM. Construct validity and minimal important difference of 6-minute walk distance in survivors of acute respiratory failure. Chest. 2015;147:1316-26. doi:10.1378/chest.14-1808.

28. McCormack MC, Bascom R, Brandt M, Burgos F, Butler S, Caggiano C, et al. Electronic Health Records and Pulmonary Function Data: Developing an Interoperability Roadmap. An Official American Thoracic Society Workshop Report. Ann Am Thorac Soc. 2021;18:1-11. doi:10.1513/AnnalsATS.202010-1318ST. 
29. Graham BL, Steenbruggen I, Miller MR, Barjaktarevic IZ, Cooper BG, Hall GL, et al. Standardization of Spirometry 2019 Update. An Official American Thoracic Society and European Respiratory Society Technical Statement. Am J Respir Crit Care Med. 2019;200:e70-88. doi:10.1164/rccm.201908$1590 \mathrm{ST}$.

30. Quanjer PH, Stanojevic S, Cole TJ, Baur X, Hall GL, Culver BH, et al. Multi-ethnic reference values for spirometry for the 3-95-yr age range: the global lung function 2012 equations. Eur Respir $\mathrm{J}$. 2012;40:1324-43. doi:10.1183/09031936.00080312.

31. Sha J, Qie G, Yao Q, Sun W, Wang C, Zhang Z, et al. Sex Differences on Clinical Characteristics, Severity, and Mortality in Adult Patients With COVID-19: A Multicentre Retrospective Study. Front Med (Lausanne). 2021;8:607059. doi:10.3389/fmed.2021.607059.

32. Segizbaeva MO, Aleksandrova NP. Respiratory Muscle Strength and Ventilatory Function Outcome: Differences Between Trained Athletes and Healthy Untrained Persons. Adv Exp Med Biol. 2021;1289:89-97. doi:10.1007/5584_2020_554.

33. Dominelli PB, Molgat-Seon Y, Sheel AW. Sex Differences in the Pulmonary System Influence the Integrative Response to Exercise. Exerc Sport Sci Rev. 2019;47:142-50. doi:10.1249/JES.0000000000000188.

34. Torres-Tamayo N, García-Martínez D, Lois Zlolniski S, Torres-Sánchez I, García-Río F, Bastir M. 3D analysis of sexual dimorphism in size, shape and breathing kinematics of human lungs. J Anat. 2018;232:227-37. doi:10.1111/joa.12743.

35. Molgat-Seon Y, Dominelli PB, Ramsook AH, Schaeffer MR, Romer LM, Road JD, et al. Effects of Age and Sex on Inspiratory Muscle Activation Patterns during Exercise. Med Sci Sports Exerc. 2018;50:1882-91. doi:10.1249/MSS.0000000000001648.

36. Mitchell RA, Schaeffer MR, Ramsook AH, Wilkie SS, Guenette JA. Sex differences in respiratory muscle activation patterns during high-intensity exercise in healthy humans. Respir Physiol Neurobiol. 2018;247:57-60. doi:10.1016/j.resp.2017.09.002.

37. Wang B, Zhou Y, Xiao L, Guo Y, Ma J, Zhou M, et al. Association of lung function with cardiovascular risk: a cohort study. Respir Res. 2018;19:214. doi:10.1186/s12931-018-0920-y.

38. Redelmeier DA, Bayoumi AM, Goldstein RS, Guyatt GH. Interpreting small differences in functional status: the Six Minute Walk test in chronic lung disease patients. Am J Respir Crit Care Med. 1997;155:1278-82. doi:10.1164/ajrccm.155.4.9105067.

39. Hayden MC, Limbach M, Schuler M, Merkl S, Schwarzl G, Jakab K, et al. Effectiveness of a ThreeWeek Inpatient Pulmonary Rehabilitation Program for Patients after COVID-19: A Prospective Observational Study. Int J Environ Res Public Health. 2021. doi:10.3390/ijerph18179001.

40. Maniscalco M, Fuschillo S, Ambrosino P, Martucci M, Papa A, Matera MG, Cazzola M. Preexisting cardiorespiratory comorbidity does not preclude the success of multidisciplinary rehabilitation in post-COVID-19 patients. Respir Med. 2021;184:106470. doi:10.1016/j.rmed.2021.106470.

41. Glöckl R, Buhr-Schinner H, Koczulla AR, Schipmann R, Schultz K, Spielmanns M, et al. Recommendations from the German Respiratory Society for Pulmonary Rehabilitation in Patients 
with COVID-19. [DGP-Empfehlungen zur pneumologischen Rehabilitation bei COVID-19].

Pneumologie. 2020;74:496-504. doi:10.1055/a-1193-9315.

42. Barker-Davies RM, O'Sullivan O, Senaratne KPP, Baker P, Cranley M, Dharm-Datta S, et al. The Stanford Hall consensus statement for post-COVID-19 rehabilitation. Br J Sports Med. 2020;54:94959. doi:10.1136/bjsports-2020-102596.

43. Wang TJ, Chau B, Lui M, Lam G-T, Lin N, Humbert S. Physical Medicine and Rehabilitation and Pulmonary Rehabilitation for COVID-19. Am J Phys Med Rehabil. 2020;99:769-74. doi:10.1097/PHM.0000000000001505.

\section{Figures}




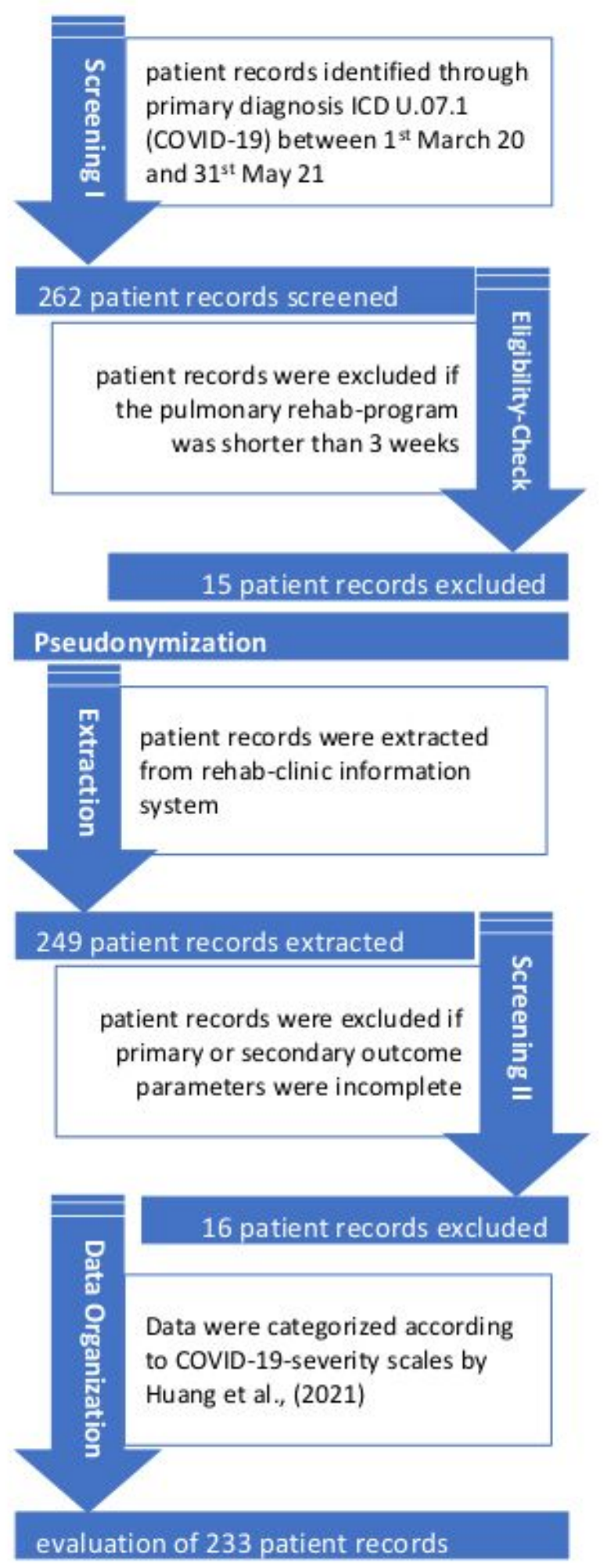

\section{Figure 1}

Flow diagram of data extraction and processing 


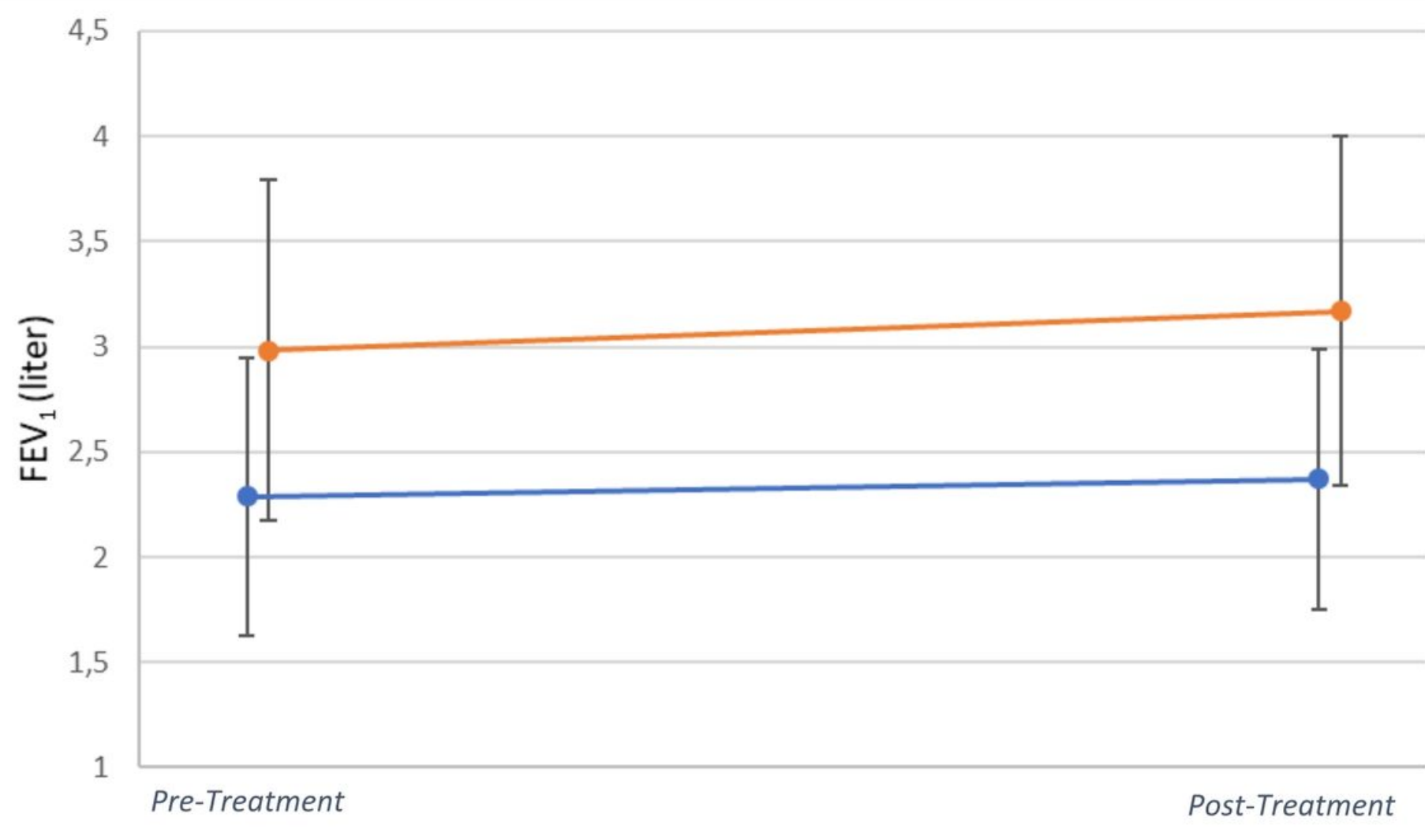

$\multimap$ Female $\longrightarrow$ Male

Figure 2

Change in forced expiratory volume in the first second $\left(\mathrm{FEV}_{1}\right)$ at rehabilitation entry and at discharge for female and male patients

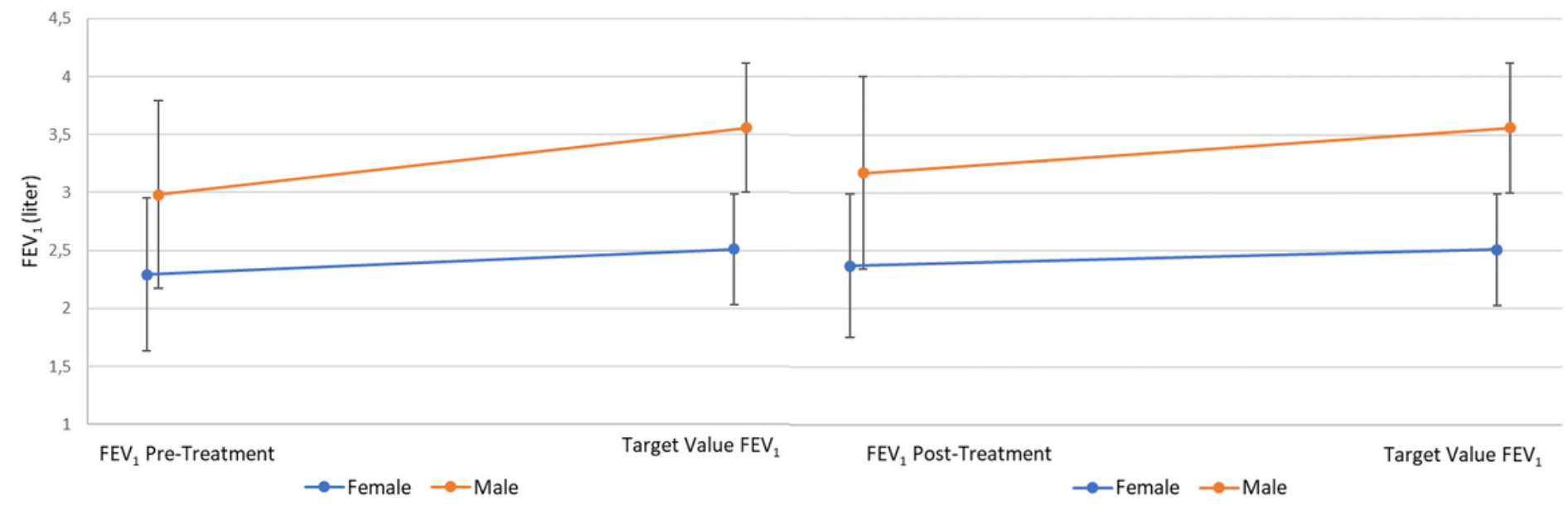

Figure 3

$\mathrm{FEV}_{1}$ comparison of actual pre- and post-treatment $\mathrm{FEV}_{1}$ values compared to reference $\mathrm{FEV}_{1}$ for female and male patients 